\title{
The Influence of Bracket Torque on External Apical Root Resorption in Bimaxillary Protrusion Patients: A Retrospective Study
}

Zhang Xiaojuan ( $D$ lhyykqzxj@163.com )

Beijing Luhe Hospital https://orcid.org/0000-0003-0464-9918

Zhou Hong

Beijing Luhe Hospital

Liao Xiangling

Beijing Luhe Hospital

Sang Jinhua

Beijing Luhe Hospital

\section{Research}

Keywords: Self-ligating brackets, torque, root resorption

Posted Date: July 13th, 2021

DOI: https://doi.org/10.21203/rs.3.rs-685870/v1

License: (9) This work is licensed under a Creative Commons Attribution 4.0 International License.

Read Full License 


\section{Abstract}

Objectives: To evaluate the difference in root resorption between standard torque self-ligating brackets and high torque self-ligating brackets in bimaxillary protrusion patients after orthodontic treatment.

Materials and Methods: Pre-treatment and post-treatment CBCT of 32 patients ( 16 treated with the high torque DamonQ 0.022 " bracket and 16 with the 0.022 " standard torque self-ligating bracket) were selected. The first premolars were extracted from all patients before treatment. After mini-screw implants were inserted into the buccal region between the second premolar and first molar, $150 \mathrm{~g}$ of force was applied to retract the upper and lower anterior teeth to close the extraction space on each side. CBCT images of all patients were taken before and after treatment. Three-dimensional reconstruction of the maxillary central incisor, lateral incisor and canine was conducted with Mimics 20.0 software. The volumes of the roots were calculated using Gomagics Studio 12.0 software. The differences between the pre-treatment and post-treatment root volumes were statistically evaluated with a paired-samples t-test.

Results: There was no statistically significant difference in root resorption degree between the two kinds of torque brackets. The patient's degree of root resorption in the high torque self-ligating group was greater than that in the standard torque group.

Conclusions: There was no significant difference in root external apical resorption between the high torque self-ligating brackets and the standard torque self-ligating brackets in bimaxillary protrusion patients.

Clinical Relevance: A comparison of the effects of different torque brackets on root resorption can provide some guidance for bracket selection in clinical work.

\section{Introduction}

Root resorption is one of the common complications of orthodontics. It has also been of great concern to orthodontic doctors in recent years. Orthodontic root resorption involves external apical root resorption (EARR) (common in the tip of the root), which is the pathological process associated with cementum and dentin loss. The factors affecting root resorption include internal and external factors. The majority of internal factors are patient factors, including genetics, sex, age, root morphology, alveolar bone density, and the type of malocclusion. External factors are primarily caused by the orthodontic treatment, such as the type of brackets, the direction of force and the amount, the duration of the applied force, premolar extractions or not, and the tooth movement distance, which are all risk factors for $\operatorname{EARR}^{[1-6]}$. There has been much research on root resorption in recent years. In terms of appliances, the impact of root resorption has been reported, such as edgewise appliances, Begg techniques, and invisible appliances ${ }^{[7-}$ 10]. The effect of self-ligating brackets and conventional brackets on root resorption has been reported ${ }^{[11-13]}$. However, there are no prior reports on the effect of torque self-ligating brackets on root resorption. 
Tooth resorption was investigated using conventional radiographs, such as periapical films, panoramic radiographs, and lateral cephalometric images. The disadvantages of these radiographs include superimposed anatomic structures, image distortion and magnification, and a lack of right-side and leftside information ${ }^{[14]}$. However, root resorption changes in three-dimensional. The 2D images cannot detect root resorption on every surface or measure the volume of root loss. As an effective imaging method for the diagnosis of orthodontic root resorption, CBCT is increasingly being used in the study of root resorption. A 1:1 ratio was used for three-dimensional reconstruction with no amplification error ${ }^{[15]}$. We can observe the images at any angle by using 3D reconstruction. Root resorption actually occurs in three dimensions, including on the buccal-lingual and mesial-distal sides. Therefore, the volume index is more accurate than the length index in reflecting the degree of root resorption. Wang ${ }^{[16]}$ has proved this point.

In view of the above, the aim of this study was to explore the different effects of root resorption in patients with maxillary protrusion using different torque brackets. Furthermore, we analysed the effects of the distance of root tip movement and the treatment time on root resorption.

\section{Materials And Methods}

This study was designed as a retrospective study, and it was conducted according to the Declaration of Helsinki principles. The study protocol was approved by the Ethics Committee of Beijing Luhe Hospital, Capital Medical University (2018LH-KS-008). Written informed consent was obtained from each participants before participating in the study.

Based on a retrospective power analysis, a total of 28 patients were required to demonstrate a clinically meaningful difference in root resorption between the appliance systems, with a 0.05 significance level and a power of $80 \%$.

In this retrospective study, 214 participants were screened in the Department of Orthodontics, Beijing Luhe Hospital, Capital Medical University. A total of 172 participants were excluded because they did not meet the inclusion criteria. Finally, 32 patients were enrolled in this study. They were divided into two groups according to the different torque brackets: a high torque self-ligating bracket group with 16 patients (Damon 3, ORMCO, USA) and a standard torque self-ligating bracket group with 16 patients. For the bracket torque data, see Table 1 .

Table 1 The bracket torque data of the two groups

\begin{tabular}{|llll|}
\hline & Maxillary central incisor & Maxillary lateral incisor & Maxillary canine \\
\hline high torque brackets & $11^{\circ}$ & $13^{\circ}$ & $22^{\circ}$ \\
\hline standard torque brackets & $7^{\circ}$ & $6^{\circ}$ & $15^{\circ}$ \\
\hline
\end{tabular}




\section{Inclusion and exclusion criteria}

\section{Inclusion criteria}

1. Patients aged $18-30$ years

2. Light or moderate anterior crowding with bimaxillary protrusion

3. CBCT was performed before and after treatment

4. All teeth erupted pre-treatment, the teeth were healthy, the maxillary incisors were without pulp disease and periapical disease, and there was no obvious root resorption

5. Extracted the four first premolars and implanted mini-screw implants

\section{Exclusion criteria}

1. Severe anterior crowding

2. Impacted teeth

3. Treatment of patients with anterior tooth trauma

4. Patients with hypoplasia

5. Patients who required orthognathic surgery or had already had surgery

6. Treatment with a conventional edgewise appliance

7. Did not receive extraction treatment

\section{Treatment procedure}

All 32 patients were treated with fixed orthodontic treatment, and the 4 first premolars were removed before treatment. The archwire sequence was 0.014 -in, $0.014 \times 0.025$-in, $0.019 \times 0.025$-in copper-nickeltitanium Damon (Ormco) and finished with $0.019 \times 0.025$-in stainless steel. The first and second premolars of the upper and lower jaws were implanted with planting nails. Mini-screws (Ningbo Cibei Medical Treatment Appliance Co., Ltd., China; diameter: $1.6 \mathrm{~mm}$; implant length: $11 \mathrm{~mm}$; screw length: 7 $\mathrm{mm}$ ) were placed between the second premolar and the first molar buccal to close the extraction space. The treatment completion time ranged from 20 to 32 months, with an average of 27.9 months. All patients were examined with the same CBCT machine (Planmeca Romexis, Finland; 0.2-mm voxel size, $90 \mathrm{kV}, 8.0 \mathrm{~mA}, 13.755$ seconds exposure time, and $351 \times 351 \times 410$ exposure field) and were operated on by the same dentist.

\section{Method of measurement}

Measurement of tooth volume: the CBCT data of the patients were imported into Mimics 20.0 software (Materialise, Leuven, Belgium), selecting the appropriate threshold for a single tooth reconstruction. The reconstructed teeth were exported to an STL file. Then, the STL file was imported into Gomagics Studio 12.0 (Materialise) for volume calculations (pictures 1 and 2). 


\section{Error study}

The measurements were performed by the same imaging specialist. After 20 days of measurement, 10 randomly selected images were repeated for three-dimensional reconstruction and measurement. The measurement error was calculated by intraclass correlation coefficient (ICC) statistics. We calculated the intra-examiner consistency. According to Roberts and Richmond ${ }^{[17]}$, the reliability is excellent if the ICC value is higher than 0.75 , acceptable if it is between 0.4 and 0.75 , and low if the ICC is smaller than 0.4 . In this study, the ICC showed excellent intra-examiner reliability. The ICC for volume measurements showed an average of $95.7 \%$, with a range from 0.875 to 0.984 , and the method presented high reproducibility.

\section{Statistical analyses}

A paired t-test was conducted to compare the degree of root resorption in each group before and after treatment. A unpaired t-test was used to assess the differences between groups. All of the data are expressed as the means with standard deviations, and the significance level was set at $5 \%$. Statistical calculations were performed with SPSS 20.0 (IBM Inc., USA).

\section{Results}

ICC statistics showed that there was almost perfect consistency between the two measures of root resorption upon the inspector evaluation. There were no statistically significant systematic errors. The casual errors were within the acceptable ranges.

There was no statistically significant difference in the comparison of the initial ages or the treatment time between the high torque group and the standard torque group (Table 2).

Table 2

Comparison of initial ages and treatment time between the high torque group and the standard torque group

\begin{tabular}{|c|c|c|c|c|c|}
\hline \multirow[t]{2}{*}{ variable } & \multicolumn{2}{|c|}{ high torque group } & \multicolumn{2}{|c|}{ standard torque group } & \multirow[t]{2}{*}{$\mathbf{P}$} \\
\hline & Mean & SD & Mean & SD & \\
\hline Initial age (years) & 24.23 & 4.76 & 24.71 & 5.46 & 0.486 \\
\hline Treatment time(months) & 26.9 & 3.72 & 25.32 & 4.60 & 0.206 \\
\hline
\end{tabular}

In the comparison between the two groups, there was a significant difference in all tooth volumes before and after treatment between the two groups (Tables 3 and 4). Root resorption occurred, and there was a significant difference after treatment in the two groups. 
Table 3

The degree of root resorption $\left(\mathrm{mm}^{3}\right)$ between pre-treatment and post-treatment for the patients with high torque

\begin{tabular}{|llllll|}
\hline Measurements, $\mathbf{m m}^{\mathbf{3}}$ & Mean & SD & Mean & SD & P \\
\hline Maxillary right central incisor & 479.47 & 36.51 & 454.98 & 38.02 & 0.000 \\
\hline Maxillary right lateral incisor & 336.24 & 24.43 & 314.84 & 21.52 & 0.000 \\
\hline Maxillary right canine & 521.59 & 52.84 & 498.64 & 50.99 & 0.000 \\
\hline Maxillary left central incisor & 480.41 & 33.81 & 455.35 & 32.56 & 0.000 \\
\hline Maxillary left lateral incisor & 341.75 & 24.34 & 320.21 & 20.83 & 0.000 \\
Maxillary left canine & 514.59 & 52.84 & 490.91 & 49.96 & 0.000 \\
\hline
\end{tabular}

Table 4

The degree of root resorption $\left(\mathrm{mm}^{3}\right)$ between pre-treatment and post-treatment for the patients in the standard torque group

\begin{tabular}{|c|c|c|c|c|c|}
\hline \multirow[t]{2}{*}{ Measurements, $\mathrm{mm}^{3}$} & \multicolumn{2}{|c|}{ Pre-treatment(T2) } & \multicolumn{2}{|c|}{ Post-treatment(T2) } & \multirow[t]{2}{*}{$\mathbf{P}$} \\
\hline & Mean & SD & Mean & SD & \\
\hline Maxillary right central incisor & 482.47 & 36.52 & 460.81 & 34.28 & 0.000 \\
\hline Maxillary right lateral incisor & 338.55 & 24.34 & 318.99 & 23.83 & 0.000 \\
\hline Maxillary right canine & 517.09 & 52.84 & 497.36 & 48.39 & 0.000 \\
\hline Maxillary left central incisor & 483.22 & 33.81 & 461.12 & 32.04 & 0.000 \\
\hline Maxillary left lateral incisor & 339.18 & 24.12 & 319.98 & 23.54 & 0.000 \\
\hline Maxillary left canine & 516.58 & 52.42 & 494.89 & 49.51 & 0.000 \\
\hline
\end{tabular}

Although the root resorption of the high torque group was higher than that of the standard torque group, there was no statistically significant difference in the degree of root resorption (Table 5). After the treatment, the two groups of teeth had different root resorptions of the same teeth. However, there was no statistically significant difference. 
Table 5

The difference in root resorption between the high torque and standard torque groups

\begin{tabular}{|llllll|}
\hline Measurements, $\mathbf{m m}^{\mathbf{3}}$ & \multicolumn{4}{l}{ high torque group(T1) } & \multicolumn{2}{l}{ standard torque group(T2) } & P \\
\cline { 2 - 5 } & Mean & SD & Mean & SD & \\
\hline Maxillary right central incisor & 24.48 & 6.31 & 21.66 & 3.75 & 0.135 \\
\hline Maxillary right lateral incisor & 21.41 & 4.1 & 19.57 & 2.41 & 0.133 \\
\hline Maxillary right canine & 22.95 & 5.4 & 19.73 & 5.33 & 0.100 \\
\hline Maxillary left central incisor & 25.07 & 4.52 & 22.09 & 4.54 & 0.073 \\
\hline Maxillary left lateral incisor & 21.54 & 5.65 & 19.20 & 4.14 & 0.191 \\
\hline Maxillary left canine & 23.48 & 5.69 & 21.69 & 6.11 & 0.398 \\
\hline
\end{tabular}

\section{Discussion}

Root resorption is one of the common complications of orthodontics, and it is also the focus of orthodontic clinical research. Previous studies have shown that the degree of root resorption is lower in patients treated with self-ligating brackets than in those treated with traditional brackets ${ }^{[18]}$. Many studies have shown that there is no difference in root resorption between self-ligating brackets and traditional brackets ${ }^{[19-21]}$. However, the self-ligating bracket has many advantages, such as a light force and a low friction force. They can reduce the operating time in the chair and bring comfort to the patients. They are widely used in orthodontics. With the development of self-ligating brackets, brackets with different torque angles have been introduced to meet the needs of clinical treatment. This experiment was designed to detect the effect of high torque brackets and standard torque brackets on root resorption in bimaxillary protrusion patients.

With the wide application of $\mathrm{CBCT}$, an increasing number of studies have been performed to evaluate root resorption by $\mathrm{CBCT}^{[22-24]}$. СВCT can accurately measure tooth and root resorption volumes, and it is a more accurate and reliable 3D measuring method for root resorption ${ }^{[19]}$. CBCT measures root resorption more often than on X-rays ${ }^{[25]}$. At present, most of the research on root resorption relies on length measurements. However, root resorption is not just a two-dimensional variation in length. It includes changes in the three-dimensional direction of the buccal tongue and the proximal middle, and the absorption on each side is slightly different. Therefore, taking the volume of the tooth used to describe the amount of root absorption is more appropriate. It can more accurately reflect root resorption [26-29]. However, research in this area is still relatively limited. To better assess the degree of root resorption, this study also used the method of measuring the tooth volume to measure the degree of root resorption before and after treatment. 
Patients with extracted teeth are more likely to develop root resorption than those who do not receive orthodontics ${ }^{[30-32]}$. In this study, all of the patients had the first premolar removed before treatment. The same orthodontist provided the same treatment, including a similar arch wire replacement throughout the entire treatment process. Mini-screw implants were inserted into the buccal region between the second premolar and first molar.

Excessive force is one of the factors involved in severe root resorption ${ }^{[33]}$. In this study, to avoid excessive force causing root resorption, $150 \mathrm{~g}$ of force was applied to retract the upper and lower anterior teeth to close the extraction space on each side ${ }^{[34]}$. All of the patients underwent CBCT by the same radiologist under the same parameters before and after treatment, which ensured good comparability between the two groups. In addition, we selected more patients (32,192 teeth) to reduce the study error caused by a small sample size.

In this study, we only considered the maxillary anterior teeth. On the one hand, the torque of the brackets in the two groups was different for the maxillary anterior teeth. On the other hand, the maxillary anterior teeth are the most prone to root resorption in orthodontic treatment ${ }^{[35-37]}$. Although the torque on the mandibular teeth was different from the standard torque, it was not included in this study. For patients with bimaxillary protrusion, a large number of anterior teeth were moved to improve the degree of protrusion ${ }^{[38]}$. Therefore, it is necessary to control the torque of the anterior teeth to acquire the desired tooth position ${ }^{[39]}$. The maxillary anterior teeth show the movement tendency of the coronal lip and the root tongue when using the high torque bracket, which is helpful to prevent torque loss in the anterior teeth. The stress expression value of the perimembrane in the high torque bracket was obviously higher than that of the standard torque bracket ${ }^{[40]}$. Case et al. ${ }^{[41]}$ reported that the effect of torque force on root resorption showed that the greater the force, the greater the root resorption scope.

In this study, the average root absorption of the high torque bracket group and the standard torque bracket group were $23.15 \mathrm{~mm}^{3}$ and $20.34 \mathrm{~mm}^{3}$, respectively. Compared with the standard torque bracket, the root resorption of the high torque self-ligating bracket was slightly higher than that of the standard torque bracket. However, the difference between them was not statistically significant. In the relatively severe root resorption between the two groups, the number and quantity of moderate and severe root resorption in the high torque group were both greater than those in the standard torque group. Yangxue et al. ${ }^{[42]}$ also showed that more torque control in the maxillary anterior teeth of the high torque group led to overall and partial root control and higher root resorption.

In this study, we found that there was no statistically significant difference in the treatment time between the groups. However, a longer treatment time led to more root resorption, which is consistent with previous studies ${ }^{[20,43,44]}$. Treatment duration is a risk factor for the development of severe EARR. However, some authors disagree ${ }^{[2,45]}$.

Some of the shortcomings of this study need attention. First, although we strictly matched the treatment group and the control group when choosing the cases, it may be difficult to avoid the effects of 
confounding factors on the results. It is best to compare the root resorption of the two types of brackets by random selection in the future. Second, although the detection process has increased the sample size compared with previous studies, the sample size is still insufficient. In future studies, we will continue to increase the sample size to correct for the effect of the sample size on the results. Finally, we still need to include more patients of different races to verify whether the two brackets affect root resorption.

\section{Conclusion}

There was no significant difference in external apical root resorption between patients treated with the high torque Damon self-ligating bracket and the high torque Damon self-ligating bracket.

\section{Declarations}

\section{Competing interests}

The authors declare that they have no competing interests.

\section{Acknowledgements}

Not applicable.

\section{Availability of data and materials}

Not applicable.

\section{Authors' contributions}

$\mathrm{HZ}$ and $\mathrm{XZ}$ designed the study, gathered the information, performed the statistical analysis and wrote the first draft of the manuscript. XL check the language. JSassisted with the statistical analysis. All authors read and approved the final manuscript.

\section{Funding}

This study was supported by Capital Medical University Nature Cultivation Fund (Code: PYZ2017003) .

\section{Ethics approval and consent to participate}

All research procedures were approved by Beijing Luhe Hospital, Capital Medical University, and informed consent was obtained from all of the participants.

\section{Consent for publication}

All patients signed a written consent form.

\section{References}


1. Acar A, Canyürek U, Kocaaga M, Erverdi N. Continuous vs. Discontinuous force application and root resorption. Angle Orthod. 1999;69:159-63.

2. Levander $E$, Malmgren $\mathrm{O}$. Evaluation of the risk of root resorption during orthodontic treatment: a study of upper incisors. Eur J Orthod. 1988;10:30-8.

3. Nanekrungsan K, Patanaporn V, Janhom A, Korwanich N. External apical root resorption in maxillary incisors in orthodontic patients: associated factors and radiographic evaluation. Imaging Sci Dent. 2012;42:147-54.

4. Weltman B, Vig KW, Fields HW, Shanker S, Kaizar EE. Root resorption associated with orthodontic tooth movement a systematic. Am J Orthod Dentofacial Orthop. 2010;137(4):462-476

5. Roscoe MG, Meira JB, Cattaneo PM. Association of orthodontic force system and root resorption: a systematic review. Am J Orthod Dentofacial Orthop. 2015;147:610- 626.

6. Alzahawi K, Færøvig E, Brudvik P, Bøe OE, Mavragani M. Root resorption after leveling with superelastic and conventional steel arch wires: a prospective study. Prog Orthod. 2014;15:1-7.

7. Janson GR, De Luca CG, Martins DR, Henriques JF, De Freitas MR. A radiographic comparison of apical root resorption after orthodontic treatment with 3 different fixed appliance techniques. Am J Orthod Dentofacial Orthop. 1999;118:262-73.

8. Mavragani M, Vergari A, Selliseth NJ, Boe OE, Wisth PJ. A radiographic comparison of apical root resorption after orthodontic treatment with a standard edgewise and a straight-wire edgewise technique. Eur J Orthod. 2000;22:665-74.

9. Beck BW, Harris EF. Apical root resorption in orthodontically treated subjects: analysis of edgewise and light wire mechanics. Am J Orthod Dentofacial Orthop. 1994;105:350-61.

10. Zhang Zhewei,Liu Yan.Root resorption during orthodontic treatment with Aligners.Chinese Journal of Orthodontics.2018,25(4):191-195

11. Leite V, Conti AC, Navarro R, Almeida M, Oltramari-Navarro P, Almeida R. Comparison of root resorption between self-ligating and conventional preadjusted brackets using cone beam computed tomography. Angle Orthod. 2012;82:1078-1082.

12. Liu XQ, Sun XL, Yang Q, Fan $\mathrm{CH}$, Chen XJ. Comparative study on the apical root resorption between self-ligating and conventional brackets in extraction patients. Shanghai Stomatol. 2012;21:460465.

13. Chen W, Haq AA, Zhou Y. Root resorption of self-ligating and conventional preadjusted brackets in severe anterior crowding class I patients: a longitudinal retrospective study. BMC Oral Health. 2015;15:115.

14. Baumrind S, Miller D, Molthen R. The reliability of head film measurements.3 Tracing superimposition. Am J Orthod. 1976;70:617-44.

15. Ahn HW, Moon SC, Baek SH. Morphometric evaluation of changes in the alveolar bone and roots of the maxillary anterior teeth before and after en masse retraction using cone-beam computed tomography. Angle Orthod.2013;83:212-21. 
16. Wang Y, He S, Guo Y, Wang S, Chen S. Accuracy of volumetric measurement of simulated root resorption lacunas based on cone beam computed tomography. Orthod Craniofac Res. 2013;16:169-76.

17. Roberts CT, Richmond S. The design and analysis of reliability studies for the use of epidemiological and audit indices in orthodontics. Br J Orthod. 1997 May;24(2):139-47

18. Lu Yiping.Imageology study of difference of root resorption after treatment of self-ligating and conventional preadjusted brackets.Stomatology,2017,37(7):635- 637.

19. Handem RH, Janson G, Matias M, et al. External root resorption with the self-ligating Damon systema retrospective study. Prog Orthod. 2016;17(1):20.

20. Qin F, Zhou Y. The influence of bracket type on the external apical root resorption in class I extraction patients - a retrospective study. BMC Oral Health. 2019;19(1):53.

21. Jacobs C, Gebhardt PF, Jacobs V, Hechtner M, Meila D, Wehrbein H. Root resorption, treatment time and extraction rate during orthodontic treatment with self-ligating and conventional brackets. Head Face Med. 2014;10:160X-10.

22. Xu SD. Explore the evaluation of adult orthodontic treatment of root resorption with CBCT. Gen J Stomatol. 2015;2:98-9.

23. Wang F, Wang JG, Zhang XZ. Examining incisor root resorption using CBCT after orthodontic treatment for adults with skeletal class III malocclusion.Tianjin Med J.2015;43:390-3.

24. Ni M, Lei Y, Chen WJ, Wu GR. Cone beam computed tomography study on the apical root resorption after orthodontic treatment in root-filled teeth. Stomatologie. 2016;36:233-6.

25. RischenRJ,BreuningKH,BronkhorstEM,Kuijpers-Jagt man AM. Records needed for orthodontic diagnosis and treatment planning:asystematicreview.PLoSOne.2013;8:e74186.

26. Sun BY, Wang L, Deng RX, Ding Y. Comparative evaluation of root resorption in mandibular incisors following the treatment of adults with skeletal class III. Prog Mod Biomed. 2012;12:1098-100.

27. Li W, Chen F, Zhang F, Ding W, Ye Q, Shi J, Fu B. Volumetric measurement of root resorption following molar mini-screw implant intrusion using cone beam computed tomography. PLoS One. 2013 Apr 9;8(4):e60962.

28. Zhang RF, Wang HM, Bai YX, Li S. Effects of orthodontic force on upper central incisor's developing roots. Beijing J Stomatol. 2016;24:335-7.

29. Aras I, Unal I, Huniler G, Aras. A Root resorption due to orthodontic treatment using self-ligating and conventional brackets : A cone-beam computed tomography study.J Orofac Orthop.2018;79:181-190

30. Iglesias-Linaresa A, Sonnenbergb B, Solanob B, Yañez-Vico R-M, Solanod E, Lindauere SJ, Flores-Mir C. Orthodontically induced external apical root resorption in patients treated with fixed appliances vs removable aligners. Angle Orthod.2017;87:3-10

31. Marcio RA, Aline SB, Thais MF, Juliana BV, Renato R, Ravindra N. A comparative study of the effect of the intrusion arch and straight wire mechanics on incisor rootresorption: a randomized, controlled trial. Angle Orthod. 2018;88:20-26. 
32. Carlos EN, Andreia CF, Ana C, Danilo PV, Mauricio AC, Renata Rodrigues AP. Comparative study of root resorption of maxillary incisors in patients treated with lingual and buccal orthodontics. Angle Orthod. 2017;87:795-800.

33. Weltman B, Vig KW, Fields HW, Shanker S, Kaizar EE. Root resorption associated with orthodontic tooth movement: a systematic review. Am J Orthod Dentofacial Orthop. 2010;137:462-76.

34. Lu Yanqin,Zeng Xxianglong,Gao Xuemei. Comparision of the friction resistance in sliding mechanics at different forces level for space closing--a nonlinear finite element study.Chinese Journal of Orthodontics.2009,16(4):207-210

35. Motokawa M, Sasamoto T, Kaku M, Kawata T, Matsuda Y, Terao A, Tanne K. Association between root resorption incident to orthodontic treatment and treatment factors. Eur $\mathrm{J}$ Orthod. 2012;34(3):350-356.

36. Maués $\mathrm{CP}$, do Nascimento RR, Vilella Ode V. Severe root resorption resulting from orthodontic treatment: prevalence and risk factors. Dental Press J Orthod. 2015;20(1):52-58.

37. Jung $\mathrm{YH}, \mathrm{Cho} \mathrm{BH}$. External root resorption after orthodontic treatment: a study of contributing factors. Imaging Sci Dent. 2011;41:17-21.

38. Lu Haiping, Fu Minkui. Clinical study of adductive maxillary incisor with square wire arch correction technique [J]. Orthodontics,1995,4(2):145-148.

39. Bai Ding, Gu Min, Zhang Jian. Incisor torque control with fixed appliance[J]. Chinese Journal of stomatology,2004,39(2):104-107.

40. Xing Bin, Wang Yucheng, Feng Feng, et al.Three-dimensional finite element analysis of the effect of brackets torque on the process of mass retraction of maxillary anterior teeth [J]. Stomatology,2018,38(5):440-444.

41. Case MA囚Faltin RM®Faltin Kखet al.Root resorptions in upper pre- molar after application of continuous torque moment, intra individual study $\mathbb{J} \mathbb{\text { Q }}$. J Orofac Orthop,2001,62(4):285-295.

42. Yang Xue,Qian Yufen.Torque control evaluated by lateral cephalometric radiography and cone-beam CT after retraction of the upper anterior teeth.Shanghai Journal of Stomatology. 2016,25(4):469-474

43. Makedonas D, Lund H, Gröndahl K, Hansen K. Root resorption diagnosed with cone beam computed tomography after 6 months of orthodontic treatment with fixed appliance and the relation to risk factors. Angle Orthod. 2011;139:e73-e81.

44. Smale I, Artun J, Behbehani F, Doppel D, Van't Hof M, Kuijpers-Jagtman AM. Apical root resorption 6 months after initiation of fixed orthodontic appliance therapy. Am J Orthod Dentofacial Orthop. 2005;128:57-67.

45. Artun J, Van't Hullenaar R, Doppel D, Kuijpers-Jagtman AM. Identification of orthodontic patients at risk of severe apical root resorption. Am J Orthod Dentofacial Orthop. 2009;135(4):448-455.

\section{Figures}


File Edit View Image Measure Segment Analyze Align Simulate 30 Tools FEA/CFD X-ray Script Help

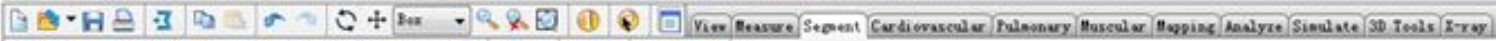
上曰S
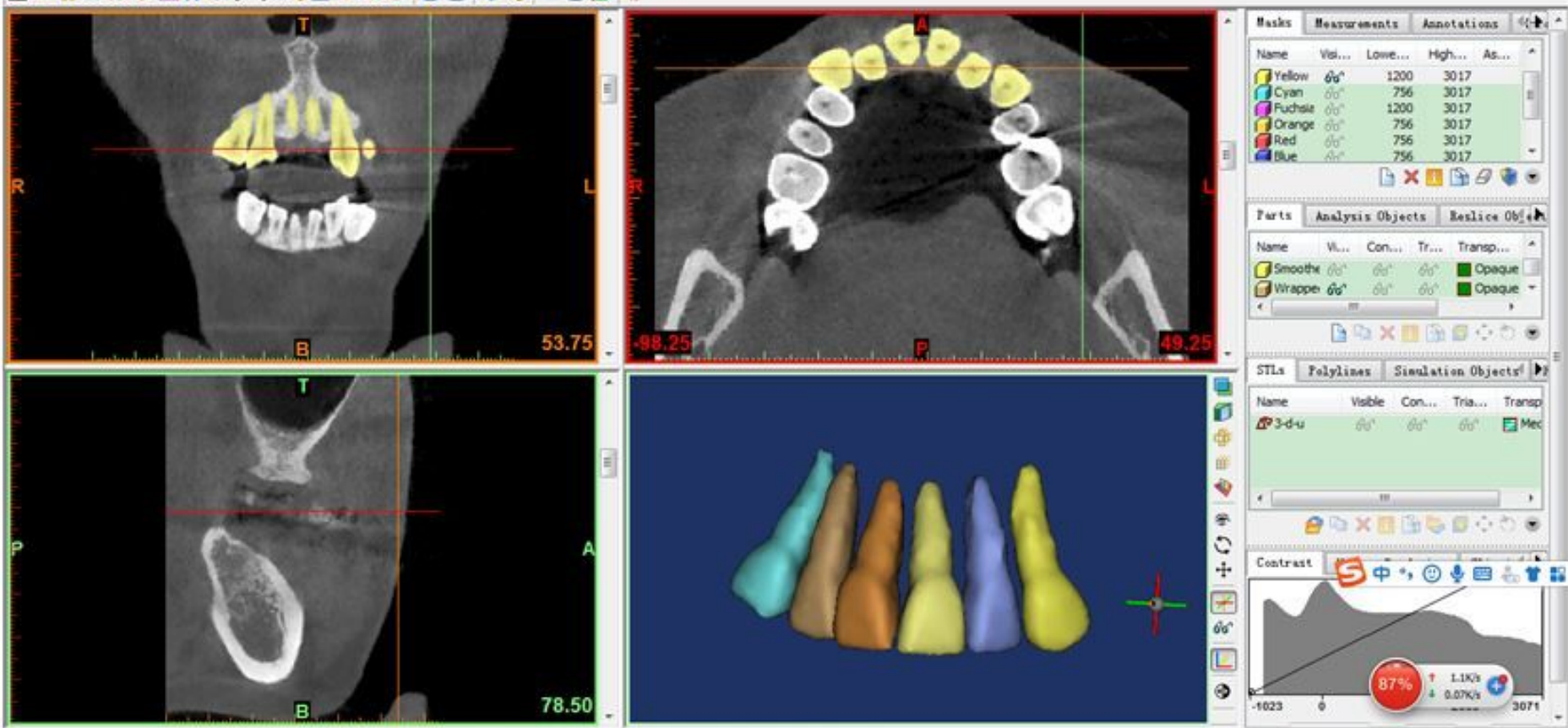

\section{Figure 1}

Three-dimensional reconstruction

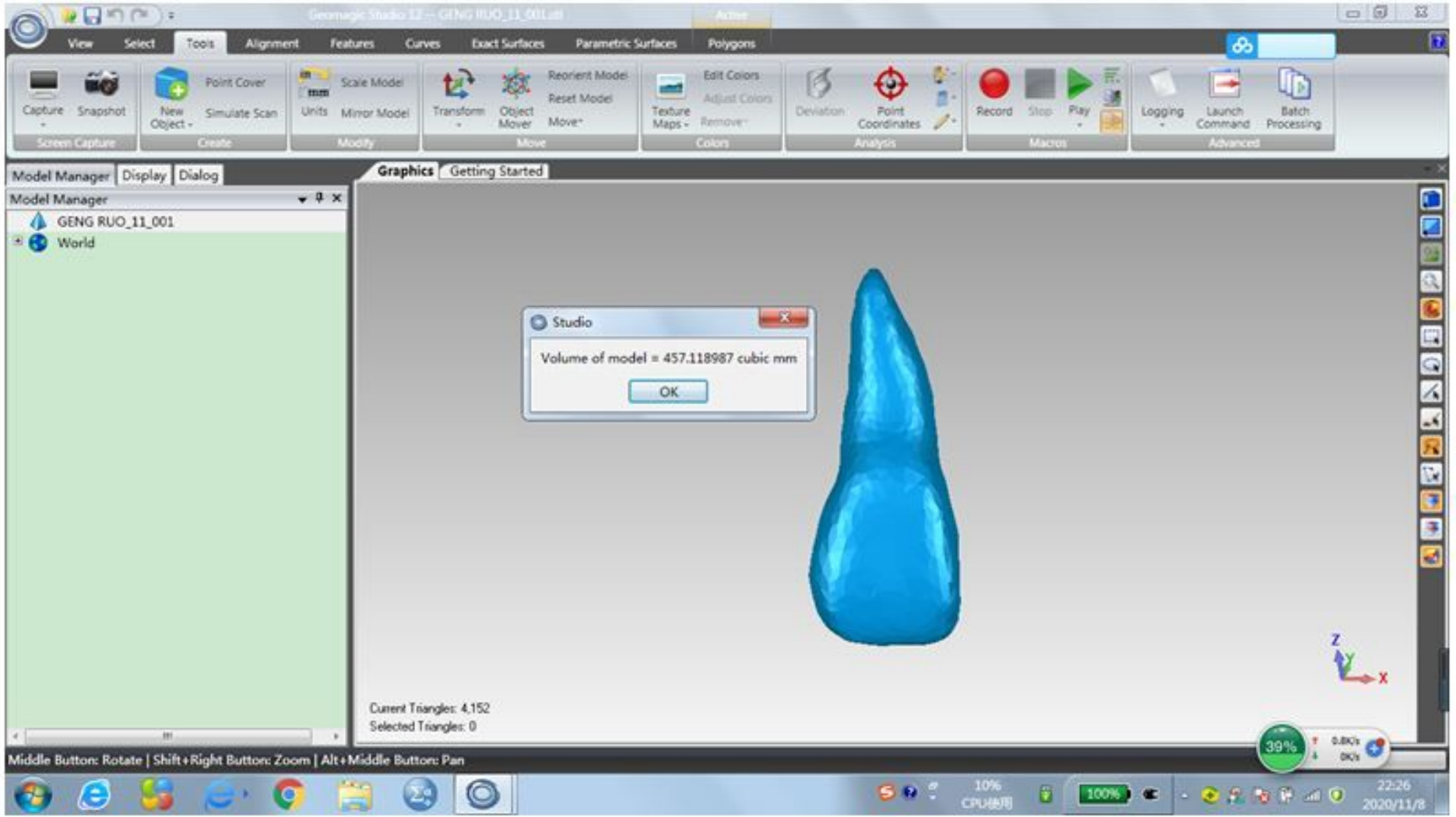


Figure 2

Volume calculation 